\title{
Efficacy study of the bioactive fraction (F-3) of Acorus calamus in hyperlipidemia
}

\author{
T.D.'Souza, S.A. M engi, S. Hassarajani*, S. Chattopadhayay*
}

C. U. Shah College of Pharmacy, S. N. D. T. University, Santacruz (W), Mumbai - 400 049, *Bio-O rganics Division, B.A.R.C, Trombay, Mumbai - 400 085, India

Received: 28.03.2007

Revised: 01.09.2007

Accepted: 27.09.2007

Correspondence to: Mengi S.

E-mail: sushmamengi@yahoo.co.in

Hyperlipidemia and its associated consequences are undisputed risk factors in the development of atherosclerosis. Moreover, a World Health Organization (WHO) survey reveals that India is predicted to have a large number of mortalities due to coronary artery disease by the year 2015. Atherosclerosis is a disease that involves the interplay of several factors. ${ }^{11}{ }^{11}$ There are three main issues to be addressed in atherosclerosis, viz., hyperlipidemia, clotting factors and oxidation of lipoproteins. These factors collectively contribute to the development and rupture of the atherosclerotic plaque. In the past decade, there has been a resurgence of interest in bioactive components of plant origin. Preliminary studies in our laboratory have indicated that the extracts of Acorus calamus have a beneficial effect on the serum lipid profile. This study investigates the effect of the bioactive fraction (F-3) obtained from the dried rhizomes of Acorus calamus on serum total cholesterol, triglycerides, highdensity lipoprotein (HDL)-cholesterol (HDL-C), LDL-cholesterol
(LDL-C) and plasma fibrinogen (procoagulant factor) levels.

The oxidative theory of atherosclerosis indicates that it is the oxidized lipoproteins that play a predominant role in conversion of macrophages to foam cells, which are the hallmark of the atherosclerotic lesion. ${ }^{|2|}$ This oxidation is often triggered and promoted by free radicals. ${ }^{[3 \mid}$ Hence, the bioactive F-3 fraction was evaluated for its free radical-scavenging effect by the DPPH method.

The F-3 fraction caused a significant decrease in the total cholesterol levels, which corresponded to a decrease in LDL levels. Thus, it is important to investigate the mechanism of action of the cholesterol-reducing effect of the fraction. Hence, we have studied its effect on the levels of the enzyme, HMGCoA reductase, Apoprotein A1 - the lipoprotein associated with HDL, having several antiatherogenic properties and Apoprotein B associated with LDL, intermediate-density lipoprotein (IDL), very low-density lipoprotein (VLDL) and chylomicrons. The 
effect of the F-3 fraction on fecal cholesterol excretion was also investigated.

\section{Materials and Methods}

Plant material and fractionation of bioactive F-3 fraction

The dried rhizomes of Acor us calamus were obtained from a commercial source and were authenticated at the Blatter's Herbarium, St. Xavier's College, Mumbai, India.

The rhizomes were powdered and subjected to continuous, hot solvent-extraction using petroleum ether, ethyl acetate and methanol successively in a Soxhlet apparatus. The concentrated methanolic extract was then added dropwise to diethyl ether and the diethyl ether-insoluble fraction was separated and designated as the bioactive F-3 fraction. A HPTLC fingerprint was determined using a Camag Linomat scanner.

\section{Animals}

Adult albino Wistar rats (200-250 g) of both sexes were used in the study. The animals were housed in standard conditions and had free access to water. The experimental procedures and the protocol were approved by the Institutional Animal Ethics Committee (IAEC).

The animals were assigned to six groups of six animals each. The animals of all the groups were given a lipid diet comprising of $77 \%$ powdered, standard pellet diet, $20 \%$ hydrogenated fats, $2 \%$ cholesterol, $1 \%$ cholic acid and $1 \mathrm{ml}$ coconut oil daily. From the $15^{\text {th }}$ day onwards, in addition to the above diet, the animals received the following treatment by the oral route until the $30^{\text {th }}$ day. Group 1 received $0.5 \mathrm{ml}$ of sodium carboxymethyl cellulose (CMC) solution (lipid diet control), groups 2 and 3 received the standard drugs fenofibrate $(20 \mathrm{mg} / \mathrm{kg}$ ) and simvastatin (4 $\mathrm{mg} / \mathrm{kg}$ ) respectively, groups 4,5 and 6 received the bioactive fraction $\mathrm{F}-3$ at doses of 10, 20 and $40 \mathrm{mg} / \mathrm{kg}$ respectively.

For the estimation of HMG-CoA reductase, three groups of rats (each group consisting of 6 animals), maintained on a standard pellet diet, were administered $0.5 \mathrm{ml}$ of sodium CMC solution (vehicle control), the standard drug simvastatin (4 mg/ $\mathrm{kg}$ ) and the bioactive F-3 fraction (40 mg/ $\mathrm{kg}$ ) for seven days. One hour after the last dose, the animals were sacrificed and the assay was carried out.

\section{Lipid profile}

The serum lipid profile was determined on day 0 (basal value), day 15 (induction value) and day 30 (post-treatment). Blood was withdrawn from the animals via retro orbital puncture under ether anesthesia. The serum was separated and the total cholesterol (TC), triglycerides (TG) and HDL-cholesterol (HDL-C) levels were estimated using commercially available kits (Noble diagnostics). LDL-cholesterol (LDL-C) levels were calculated using Friedewald's formula. ${ }^{[4]}$

\section{Fibrinogen}

The plasma fibrinogen levels were estimated based on the thrombin clotting time using Dade Behring kits (Dade Behring Marburg Gmbh, Germany). Briefly, the diluted plasma was mixed with Dade Owren's Veronal buffer. The reconstituted thrombin reagent maintained at $37^{\circ} \mathrm{C}$, was then added to the buffered plasma in the ratio 1:2 and the thrombin clotting time noted. The fibrinogen concentration of the plasma samples was determined by a standard curve of concentration $(\mathrm{mg} / \mathrm{dl}) \mathrm{vs}$ thrombin clotting time.

\section{Apoprotein A1, Apoprotein B}

The above parameters were determined by a turbidimetric immunoassay using Erba Mannheim Diagnostic kits. Briefly, the diluted serum was mixed with phosphate-buffered saline containing polyethylene glycol and sodium azide. To this was added the antiserum followed by mixing and incubation at room temperature for five mins. The optical density (OD) was read both before and after adding the antiserum at $340 \mathrm{~nm}$ and the difference in the readings $(\Delta O D)$ was calculated. The Apoprotein concentrations were determined by a standard curve of concentration (mg/dl) vs $\Delta O D$.

\section{HMG-CoA reductase activity}

The activity of the enzyme HMG-CoA reductase was determined by the method described by Venugopala Rao and Ramakrishnan. ${ }^{[5]}$ The method estimates the HMG-CoA/ mevalonate ratio as an index of the activity of HMG-CoA reductase. Briefly, the liver tissue was removed as quickly as possible and a $10 \%$ homogenate was prepared in saline arsenate solution. The homogenate was deproteinized using an equal volume of dilute perchloric acid and allowed to stand for five mins followed by centrifugation. To $1 \mathrm{ml}$ of the filtrate, $0.5 \mathrm{ml}$ of freshly prepared hydroxylamine reagent (alkaline hydroxylamine reagent in the case of HMG-CoA) was added. It was mixed and $1.5 \mathrm{ml}$ of ferric chloride reagent was added after five minutes. The absorbance was read after ten mins at $540 \mathrm{~nm}$ vs a similarly treated saline arsenate blank. The ratio of HMG-CoA/mevalonate was calculated.

Fecal cholesterol excretion

Fecal matter was collected during the last three days of the treatment period. The dried and powdered fecal matter was extracted with chloroform: methanol (2:1). The resultant extract was then analyzed for cholesterol content in a manner similar to that of the serum. The cholesterol excreted in the fecal matter $(\mathrm{mg} / \mathrm{g})$ was calculated.

\section{Free radical scavenging activity}

The DPPH (Diphenyl picryl hydrazyl) free radical scavenging method was employed. ${ }^{[6]}$ The DPPH radical is a stable, free radical and gives a strong absorption band at $517 \mathrm{~nm}$. Various concentrations of the bioactive F-3 fraction were added to DPPH in methanol, the initial and final absorbance was read at $517 \mathrm{~nm}$ and the percentage inhibition was calculated. The concentration at which there was a $50 \%$ inhibition was considered as the $\mathrm{IC}_{50}$. HPTLC studies

The HPTLC fingerprint was obtained using a Camag Linomat IV applicator and detector. The plates were observed under ultraviolet (UV) after spraying with various reagents.

Statistical analysis

Results are expressed as mean \pm SE (standard error) and subjected to one-way analysis of variance (ANOVA) followed by Dunnett's test and values with $P<0.05$ were considered to be statistically significant.

\section{Results}

Lipid profile

Administration of a lipid diet resulted in a significant increase $(P<0.05)$ in total serum cholesterol, triglycerides and LDL levels [Figure 1]. 
Figure 1: Effect of lipid diet on the serum lipid profile in rats. Each column represents mean \pm SE of the concentration $(\mathrm{mg} / \mathrm{dl})$ of each of the parameters on day 0 (basal value) and day 15 (induction value) for the 36 rats included in the study. ${ }^{*} P<0.05$, induction values compared to basal values.

$\mathrm{TC}=$ Total Cholesterol

$\mathrm{TG}=$ Triglycerides

HDL-C = High-Density Lipoprotein-Cholesterol

LDL-C = Low-Density Lipoprotein-Cholesterol

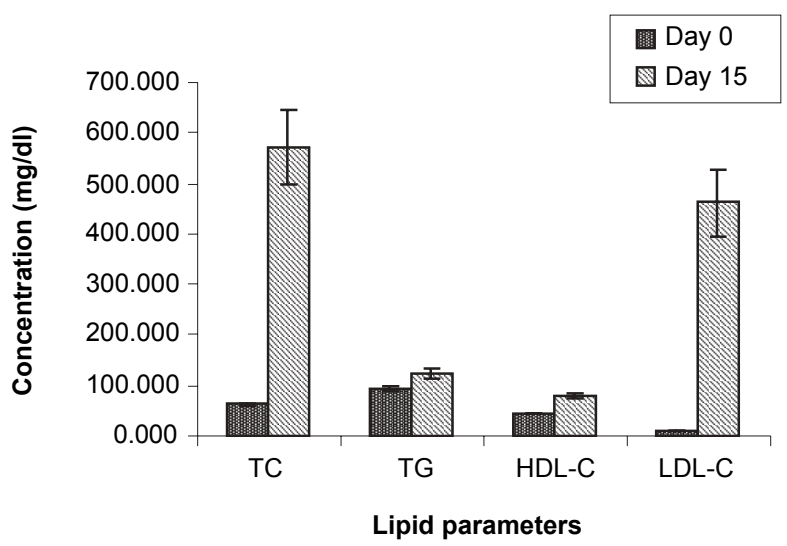

Administration of the standard drugs fenofibrate and simvastatin resulted in significant decreases by 47.14 and $33.59 \%(P<0.05)$ respectively in total cholesterol levels. Doses of 10,20 and $40 \mathrm{mg} / \mathrm{kg}$ of the F-3 fraction demonstrated 11.42, 23.76 and $31.18 \%$ decreases in total cholesterol levels. The decrease was found to be significant $(P<0.05)$ at the doses of 20 and $40 \mathrm{mg} / \mathrm{kg}$. The serum triglyceride levels were significantly $(P<0.05)$ decreased only by the standard drug fenofibrate $(53.38 \%)$, while none of the treatment groups showed a significant effect on serum HDL levels.

The effect of the treatment groups on serum LDL was similar to that on total cholesterol. The standard drugs fenofibrate and simvastatin demonstrated significant decreases by 65.59 and $42.64 \%(P<0.05)$ respectively. Doses of 10,20 and $40 \mathrm{mg} / \mathrm{kg}$ of the F-3 fraction produced $4.93,31.96$ and $36.48 \%$ decreases respectively in serum LDL levels that was significant $(P<0.05)$ at the 20 and $40 \mathrm{mg} / \mathrm{kg}$ dose levels [Table 1].

Fibrinogen

The lipid diet produced a $41.90 \%$ increase $(P<0.05)$ in the
Figure 2: Per cent changes in fibrinogen levels after treatments. Each column represents mean \pm SE of the percentage change in plasma fibrinogen levels from day 0 to day $30, n=6$ for each group.

${ }^{*} P<0.05$ compared to the Lipid diet Control

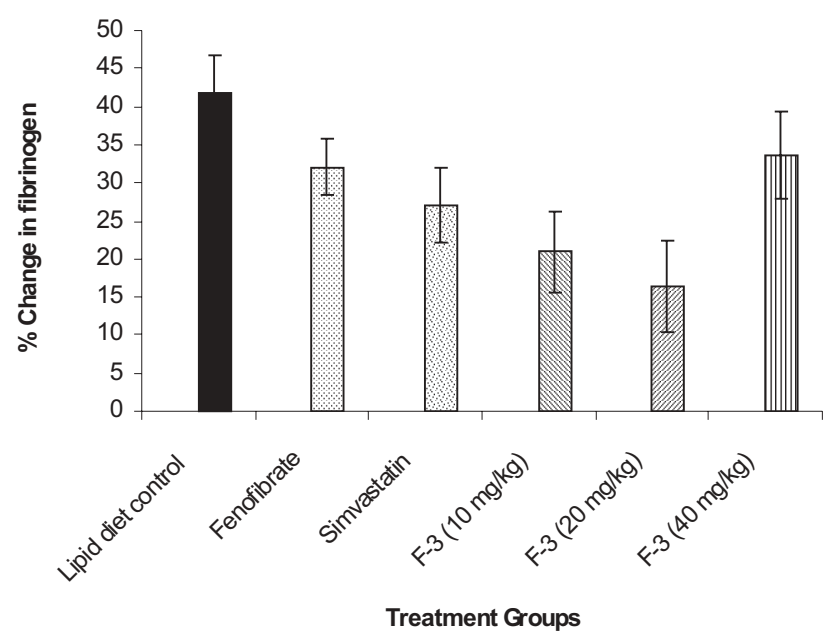

plasma fibrinogen levels. The standard drugs fenofibrate and simvastatin marginally attenuated this increase, however this attenuation was not found to be significant. Doses of 10 and $20 \mathrm{mg} / \mathrm{kg}$ of the fraction demonstrated a significant $(P<0.05)$ attenuation of the raised plasma fibrinogen levels. However, at the higher dose of $40 \mathrm{mg} / \mathrm{kg}$, the fraction failed to produce a significant effect [Figure 2].

\section{Apoprotein A and Apoprotein B}

The fraction at 20 and $40 \mathrm{mg} / \mathrm{kg}$ showed an increase in Apoprotein A-1 levels, however this increase was not found to be significant. The standard drug simvastatin produced a significant reduction in Apoprotein $B$ levels as well as a significant increase in the Apo A-1/ Apo B ratio [Table 2].

HMG-COA reductase activity

The ratio of HMG-CoA / mevalonate was significantly $(\mathrm{P}<$ 0.05 ) increased by the standard drug simvastatin as well as the $40 \mathrm{mg} / \mathrm{kg}$ dose of the bioactive F-3 fraction [Table 3].

Fecal cholesterol excretion

Doses of 10, 20 and $40 \mathrm{mg} / \mathrm{kg}$ of the fraction induced 7.9 , 23.27 and $48.45 \%$ increases respectively in the cholesterol

\section{Table 1}

Effects of various treatments on lipid profile in hyperlipidemic rats after 15 days of treatment

\begin{tabular}{|c|c|c|c|c|c|c|}
\hline $\begin{array}{l}\text { Parameter } \\
\text { ( } \mathrm{mg} / \mathrm{dl})\end{array}$ & $\begin{array}{l}\text { Lipid diet } \\
\text { Control }\end{array}$ & $\begin{array}{l}\text { Fenofibrate } \\
20 \mathrm{mg} / \mathrm{kg}\end{array}$ & $\begin{array}{l}\text { Simvastatin } \\
4 \mathrm{mg} / \mathrm{kg}\end{array}$ & $\begin{array}{c}F-3 \\
10 \mathrm{mg} / \mathrm{kg}\end{array}$ & $\begin{array}{c}F-3 \\
20 \mathrm{mg} / \mathrm{kg}\end{array}$ & $\begin{array}{c}F-3 \\
40 \mathrm{mg} / \mathrm{kg}\end{array}$ \\
\hline Total cholesterol & $615.00 \pm 206.2$ & $\begin{array}{c}177.56 \pm 78.08 \\
(47.14 \pm 8.04)^{\star}\end{array}$ & $\begin{array}{c}225.76 \pm 65.16 \\
(33.59 \pm 6.49)^{*}\end{array}$ & $\begin{array}{c}614.80 \pm 86.20 \\
(11.42 \pm 4.82)\end{array}$ & $\begin{array}{c}397.62 \pm 84.99 \\
(23.76 \pm 6.01)^{*}\end{array}$ & $\begin{array}{c}308.65 \pm 55.58 \\
(31.18 \pm 4.39)^{\star}\end{array}$ \\
\hline Triglycerides & $78.27 \pm 13.44$ & $\begin{array}{c}52.04 \pm 4.66 \\
(53.38 \pm 4.78)^{\star}\end{array}$ & $79.53 \pm 7.40$ & $101.81 \pm 16.58$ & $80.78 \pm 11.05$ & $103.87 \pm 14.23$ \\
\hline High-density lipoprotein & $66.82 \pm 22.00$ & $54.13 \pm 8.48$ & $65.72 \pm 17.67$ & $70.02 \pm 10.33$ & $71.21 \pm 16.29$ & $56.00 \pm 10.93$ \\
\hline Low-density lipoprotein & $502.06 \pm 231.03$ & $\begin{array}{c}187.84 \pm 113.29 \\
(65.59 \pm 3.22)^{\star}\end{array}$ & $\begin{array}{l}209.92 \pm 91.72 \\
(42.64 \pm 16.20)^{*}\end{array}$ & $\begin{array}{r}462.76 \pm 172.44 \\
(4.93 \pm 17.39)\end{array}$ & $\begin{array}{c}361.09 \pm 86.72 \\
(31.96 \pm 1.79)^{*}\end{array}$ & $\begin{array}{c}235.46 \pm 78.66 \\
(36.48 \pm 7.76)^{\star}\end{array}$ \\
\hline
\end{tabular}

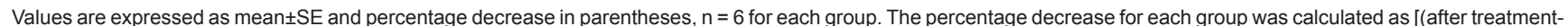
before treatment) / before treatment] $\times 100 ;{ }^{*} P<0.05$ compared to the Lipid diet Control 
Table 2

Effects of various treatments on Apoprotein levels in hyperlipidemic rats after 15 days treatment

\begin{tabular}{|c|c|c|c|c|c|c|}
\hline $\begin{array}{l}\text { Parameter } \\
\text { (mg/dl) }\end{array}$ & $\begin{array}{l}\text { Lipid diet } \\
\text { Control }\end{array}$ & $\begin{array}{l}\text { Fenofibrate } \\
20 \mathrm{mg} / \mathrm{kg}\end{array}$ & $\begin{array}{l}\text { Simvastatin } \\
4 \mathrm{mg} / \mathrm{kg}\end{array}$ & $\begin{array}{c}F-3 \\
10 \mathrm{mg} / \mathrm{kg}\end{array}$ & $\begin{array}{c}F-3 \\
20 \mathrm{mg} / \mathrm{kg}\end{array}$ & $\begin{array}{c}F-3 \\
40 \mathrm{mg} / \mathrm{kg}\end{array}$ \\
\hline Apo A1 & $13.13 \pm 4.73$ & $5.14 \pm 1.11$ & $9.86 \pm 5.74$ & $14.72 \pm 4.91$ & $22.36 \pm 5.83$ & $22.50 \pm 5.13$ \\
\hline Apo B & $20.29 \pm 5.89$ & $43.05 \pm 27.59$ & $3.74 \pm 1.85^{\star}$ & $33.33 \pm 16.98$ & $25.83 \pm 16.79$ & $29.99 \pm 8.08$ \\
\hline Apo A1/B & $0.87 \pm 0.24$ & $0.27 \pm 0.14$ & $2.42 \pm 0.44^{*}$ & $3.46 \pm 1.94$ & $1.43 \pm 0.67$ & $1.14 \pm 0.37$ \\
\hline
\end{tabular}

Values are expressed as mean \pm SE, $\mathrm{n}=6$ for each group, ${ }^{*} P<0.05$ compared to the lipid diet control

\section{Table 3}

\begin{tabular}{|c|c|}
\hline Group & HMG-CoA/ mevalonate ratio \\
\hline Vehicle control & $5.83 \pm 0.11$ \\
\hline Simvastatin & $7.89 \pm 0.49^{*}$ \\
\hline $\mathrm{F}-3(40 \mathrm{mg} / \mathrm{kg})$ & $7.78 \pm 0.37^{*}$ \\
\hline
\end{tabular}

Values are expressed as mean \pm SE, $\mathrm{n}=6$ for each group. ${ }^{*} P<0.05$ compared to the vehicle control

excreted in the fecal matter. The difference in cholesterol excretion was significant $(P<0.05)$ at the dose of $40 \mathrm{mg} / \mathrm{kg}$ when compared with the Lipid diet control group [Figure 3].

Free radical-scavenging activity

The F-3 fraction demonstrated an appreciable free radicalscavenging effect. The $\mathrm{IC}_{50}$ of the fraction was $324 \mu \mathrm{g} / \mathrm{ml}$.

HPTLC studies

HPTLC fingerprinting indicated that the bioactive F-3 fraction is composed of five components that gave a colour reaction with anisaldehyde sulphuric acid and vanillin sulphuric acid reagents.

\section{Discussion}

In the present study, we have investigated the effect of the bioactive F-3 fraction on experimentally induced hyperlipidemia

Figure 3: Effects of treatments on fecal cholesterol excretion after 15 days treatment. Each column represents mean \pm SE of the fecal cholesterol $(\mathrm{mg} / \mathrm{g})$ of the various groups

$\mathrm{n}=6{ }^{*} \mathrm{P}<0.05$

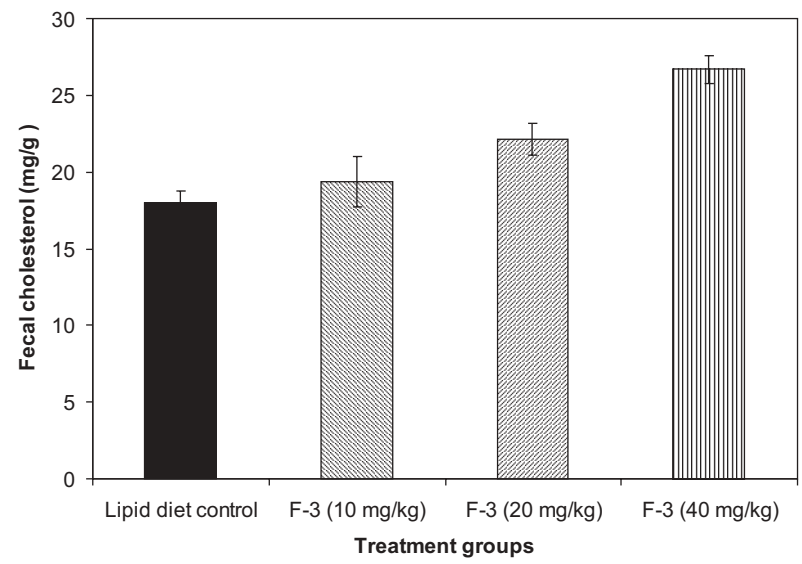

in rats. Doses of 20 and $40 \mathrm{mg} / \mathrm{kg}$ of the fraction demonstrated a significant decrease in the raised diet-induced levels of total cholesterol. Additionally, this decrease corresponded specifically to a reduction in LDL-C levels. At a dose of $40 \mathrm{mg} /$ $\mathrm{kg}$, these effects were comparable with that of the standard drugs fenofibrate and simvastatin. The fraction, however, failed to have a significant effect on serum TG and HDL-C levels. Fibrinogen is an acute phase protein that is a contributing factor in thrombotic events in atherosclerosis. The results of the study indicated that the fraction has a potential to marginally, but significantly, attenuate the raised plasma fibrinogen levels.

Apoproteins provide the structural element to the lipoprotein particles as well act as ligands for specific enzymes and receptors in lipoprotein metabolism. Measurement of the levels of the important lipoproteins such as Apo A and Apo $B$ can throw light on lipid metabolism and the effect of the various drugs on the same. Additionally, the Apoprotein A class of lipoprotein, besides being associated with the HDL particle, is known to play important antioxidant and anti-inflammatory roles in atherosclerosis. ${ }^{[7]}$

At 20 and $40 \mathrm{mg} / \mathrm{kg}$ dose levels, the fraction showed an increase in Apo A1 levels, however this increase was not found to be significant. Scrutiny of the data revealed that this was due to the fact that while $50 \%$ of the animals in the group showed a significant increase $(P<0.05, n=3)$ in the Apo A1 levels, the other $50 \%$ of the animals showed no such effect on the Apo A1 levels. Only the standard drug simvastatin showed a significant decrease in the raised Apo B levels. Apo B secretion by the liver is regulated by factors such as rate of cholesterol biosynthesis, availability of triglycerides and cholesterol esters. ${ }^{[8,9]}$ Statins are known to have an inhibitory effect on cholesterol biosynthesis which could result in decreased Apo B secretion by the liver. ${ }^{[8]}$

Since the results of the study indicated that the bioactive F-3 fraction has a beneficial effect on lipid profile, we have investigated its mechanism of action. Cholesterol homeostasis is maintained by the control of the two process, viz., cholesterol biosynthesis in which HMG-Co-A reductase catalyzes the ratelimiting process and cholesterol absorption of both dietary cholesterol and cholesterol cleared from the liver through biliary secretion.

The HMG-CoA/mevalonate ratio has an inverse relationship to the activity of HMG-CoA reductase. The results of the study indicated that the activity of the enzyme is significantly depressed by the bioactive F-3 fraction as is evidenced by the increase in the ratio.

Furthermore, there was also an increase in the cholesterol content of the fecal matter indicating that the bioactive F-3 
fraction promoted the excretion of cholesterol. Bioactive fractions of plant origin are often known to attenuate hyperlipidemia by this mechanism.

From the results of this study, we could conclude that the F-3 fraction demonstrated its cholesterol-reducing effects via inhibition of cholesterol biosynthesis and promotion of cholesterol excretion. In addition, the fraction had an appreciable free radical-scavenging activity. Thus, the results of the present study indicate that the bioactive F-3 fraction could have a potentially beneficial effect in atherosclerosis associated with hyperlipidemia.

\section{Acknowledgment}

Board of Research in Nuclear Sciences (BRNS), Bhabha Atomic Research Centre (B.A.R.C.) for financial support.

\section{References}

1. Singh RB, Mengi SA, Xu YJ, Arneja AS, Dhalla NS. Pathogenesis of atherosclerosis: A multifunctional process. Exp Clin Cardiol 2002;26:1-9.
2. Itabe H. Oxidized low density lipoproteins: What is understood and what remains to be clarified? Biol Pharm Bull 2003;26:1-9.

3. Witzhum JL. The oxidation hypothesis of atherosclerosis. Lancet 1994;344:7935.

4. Friedwald WT, Levy RI, Fredrickson DS. Estimation of the concentration of low density lipoprotein cholesterol without the use of the preparative ultracentrifuge. Clin Chem 1972;18:499-502.

5. Rao AV, Ramakrishnan S. Indirect assessment of hydroxymethylglutaryl-Co-A reductase (NADPH) activity in liver tissue. Clin Chem 1975;21:1523-5.

6. Soni K, Kumar PS, Saraf MN. Free radical scavenging and antilipid peroxidation activity of Tephrosia purpurea Linn. Indian J Pharm Sci 2003;65:27-30.

7. Garner B, Waldeck AR, Wittig PK, Rye KA, Stocker R. Oxidation of high density lipoproteins II Evidence for direct reduction of lipid hydroperoxides by methionine residues of apolipoproteins A-I and A-II. J Biol Chem 1998;273:6088-95.

8. Burnett JR, Wilcox LJ, Telford DE, Kleinstiver SJ, Barrett PH, Newton RS, et al. Inhibition of HMG-CoA reductase by atorvastatin decreases both VLDL and LDL apolipoprotein B production in miniature pigs. Arterioscler Thromb Vasc Biol 1997;17:2589-600.

9. Dixon J, Furukawa S, Ginsberg HN. Oleate stimulates apolipoprotein B-containing lipoproteins from HepG2 cells by inhibiting early intracellular degradation of apolipoprotein B. J Biol Chem 1991;266:5080-6. 